\title{
La mediación biopedagógica desde una perspectiva ética
}

\section{Ethical Perspective of Biopedagogical Mediation}

\author{
lleana Castillo Cedeño' \\ Centro de Investigación y Docencia en Educación, Vicedecanato \\ Universidad Nacional \\ Heredia, Costa Rica \\ ileana.castillo.cedeno@una.cr \\ Rocío Castillo Cedeño \\ División de Educación Básica, Centro de Investigación y Docencia en Educación \\ Universidad Nacional \\ Heredia, Costa Rica \\ rociocastillocedeno@gmail.com
}

Recibido 28 de febrero de 2013 • Corregido 10 de marzo de 2013 • Aceptado 13 de marzo de 2013

Resumen. Este ensayo aborda el tema de la mediación biopedagógica desde una perspectiva ética, considera la trascendencia que tiene el situar a la educación desde un paradigma alternativo, donde pedagogía y vida se complementan para atender el sentido emancipador del proceso educativo. El objetivo es aportar a la reflexión y la acción sobre la mediación pedagógica y su inherente concatenación con la ética. Se parte de la premisa de la necesidad de cultivar el sentido de la existencia, desde principios y valores que exalten la vida en su multidimensionalidad y complejidad. La educación como proyecto político debe responder al reto de preparar para una ciudadanía planetaria, esfuerzo compartido que compromete a todo ser humano a trabajar por una verdadera transformación social y, por tanto, mental, para obtener mejores estados de bienestar personal y social. Se requiere direccionar todas las energías y sabiduría para poder visualizar la transformación humana que tanto demanda el planeta.

1 Doctora en Educación con mención en Mediación Pedagógica. Universidad de la Salle, Costa Rica. Egresada del Doctorado en Diseño Curricular y Evaluación Educativa, de la Universidad de Valladolid, España. Magíster en Psicopedagogía. Magíster en Educación Preescolar. Especialista en Didáctica de la Educación del Consumidor. Universidad de Valladolid, España. Profesora, bachiller y licenciada en Ciencias de la Educación con énfasis en Educación Preescolar, Universidad Nacional de Costa Rica. Actualmente se desempeña como investigadora y ocupa el cargo de vicedecana del Centro de Investigación y Docencia en Educación de la Universidad Nacional de Costa Rica. Autora de varias publicaciones sobre educación, pedagogía y universidad en revistas de su especialidad. Coautora del libro: Equidad y justicia social. Un reto para el liderazgo pedagógico.

2 Doctora en Educación con mención en Mediación Pedagógica, Universidad de la Salle, Costa Rica. Magíster en Administración Educativa y en Psicopedagogía. Profesora y bachiller en Ciencias de la Educación con énfasis en Educación Preescolar. Durante 5 años se desempeñó como decana de la Facultad de Educación de la Universidad De La Salle, Costa Rica y durante un año como vicerrectora académica en esta misma Universidad. Actualmente, se desempeña como académica e investigadora de la División de Educación Básica del Centro de Investigación y Docencia en Educación de la Universidad Nacional de Costa Rica. Autora del libro: La conciencia cósmica en la primera infancia: Reflexiones paradigmáticas, propuestas biopedagógicas y un acercamiento a la espiritualidad de las niñas y los niños. 
URL: http://www.una.ac.cr/educare

CORREO: educare@una.cr

Palabras claves. Mediación, biopedagogía, vida, educación, ética, solidaridad, responsabilidad, diálogo, convivencia, comunicación, interrelaciones, aprendizaje, Costa Rica, Revista Electrónica Educare.

\begin{abstract}
This paper on the ethical perspective of biopedagogical mediation draws attention to the importance of addressing education from an alternative paradigm where both pedagogy and life complement each other in response to the emancipatory character of the educational process. The purpose of this study is to contribute to the thoughts and actions on pedagogical mediation and its inherent bond to ethics. The paper is based on the premise of the need to nourish the sense of existence, from the principles and values that exalt the multidimesionality and complexity of life. Education, as a political project shall face the challenge to prepare society for a planetary citizenship, a shared effort that brings every human being to work for a real social-and mental-transformation, in order to reach higher levels of personal and social welfare. It is necessary to address all energies and wisdom to visualize the human transformation so demanded by the planet.
\end{abstract}

Keywords. Mediation, bio-pedagogy, life, education, ethics, solidarity, responsibility, dialogue, coexistence, communication, relationships, learning.

\title{
Mediación pedagógica: Un primer encuentro con la ética del cuidado
}

El abrumador contexto sociohistórico, político y económico hace que se viva, en gran medida, en un mundo de ligereza, donde se sigue la lógica de la reproducción del modelo economicista neoliberal, el cual persigue que la educación continúe al servicio de los intereses de la cultura dominante, enfocada en la mercantilización del mundo y de la vida. El sistema educativo, como sistema global de interrelaciones y comunicación, sigue perpetuando la fragmentación del conocimiento, la visión restringida del potencial del ser humano para generar procesos pedagógicos que pongan fin a las ataduras de la lógica reproduccionista y colonialista que invade la ética de la vida.

Las ideologías que legitiman la violencia estructural, perpetuadoras de desigualdades siguen presentes en la educación: una lucha de poderes fundamentados en intereses individuales que forjan conflictos perennes de convivencia. De ahí, que conservarse como una persona aprendiente, crítica, propositiva, solidaria y creativa se convierte en una utopía plasmada en discursos dentro del complejo modelo curricular en todos los niveles del sistema educativo.

Desde este marco de referencia, el derecho a una educación con altos valores y principios fundados en la ética, constituye todo un reto que exige la voluntad de unirse en un proyecto compartido que se resista al Estado opresor y depredador, para - desde la esperanza de una educación democrática- aspirar y trabajar por una verdadera transformación mental que conduzca a estados de bienestar personal y social.

Desde una visión biopedagógica, como ser vivo, se está en constante aprendizaje, se vive en comunidades aprendientes, sistemas de interaprendizaje, interdependencia, transformación, los cuales Assman (2002) llama "nichos ecológicos" o "comunidad ecológica". Se vive en sociedades altamente complejas en las que entran en juego relaciones; adaptaciones que involucran flexibilidad y permanente autoconstrucción para la trascendencia, más allá de lo efímero. 
En un sentido pedagógico, según Gutiérrez (2004):

El aprendizaje solo es posible cuando el educando se moviliza y se compromete en el proceso de aprendizaje. Por lo tanto, la misión del mediador no será enseñar, sino promover la movilización, el compromiso, adaptación, motivación, animación. El reto del educando para la vida será desarrollar su capacidad de inventar, crear nuevos comportamientos, nuevas reacciones y nuevas respuestas. (p. 87)

En otras palabras, aprender es parte de la relación dinámica con la vida, la cual se caracteriza por la convivencia, interrelaciones que potencian la autorrealización a la luz de la cocreación. Aprender en la convivencia no se logra, sino dentro de un marco ético de relacionalidad donde la comunicación permite encuentros desde donde surge la ética dialógica, sustento clave de una educación alternativa, según Pasillas (2005):

(...) ésta busca, en sus diferentes vertientes, convenir la manera de hacer posible una comunicación que sea ajena a toda forma de dominio y de ejercicio del poder y de violencia, de tal modo que los participantes en esa eventual forma de comunicación sean libres de plantear sus aspiraciones, sus pretensiones y requerimientos sin temor a respuestas desenfrenadas por parte de los dominadores, de los poderosos (...). (p. 1151)

Implica sin duda, repensar el modo en que se desarrollan las experiencias pedagógicas -tanto en ambientes formales como no formales- para priorizar vivencias con sentido auténtico, que permitan el aprender a pensar, sentir y vivir desde el fundamento ético. Según Osorio y Weinstein (1995) “(...) la ética supone una reflexión y una evaluación de la conducta de las personas en referencia al efecto de dichas acciones humanas sobre el colectivo humano y su entorno" (p. 222).

Al reflexionar acerca de estas ideas, surge la pregunta del: ¿cómo?, cuya respuesta va de la mano con clarificar la visión paradigmática que ha prevalecido en las instituciones educativas y con la necesidad de visualizar formas de relacionamiento que acerquen a cada persona a las otras y al entorno desde el cuidado y la ternura. Alvarado (2007) expone que:

(...) entre educación y epistemología, para bien o para mal, hay una pauta que conecta. La educación siempre será determinada por la epistemología que la sustenta. Por ello la educación actual no se superará a sí misma, si no se libera de la pesada ancla que le impide navegar libre por los cielos de nuevos mundos y tiempos. Esa ancla en la epistemología de Bacon, Locke, Newton y Descartes, luego de cortar la cual, podremos construir en su lugar una forma de conocer que permita a los seres humanos vivir en la naturaleza y no contra ella". (pp. 90-91) 
URL: http://www.una.ac.cr/educare

CORREO: educare@una.cr

Definitivamente, es muy difícil vivenciar la ética, si la pedagogía no ha permitido que las personas crezcan en la comprensión de los demás, si las dinámicas que se proponen fomentan la competitividad y la exclusión; si justifican la violencia que va desde la imposición de contenidos hasta la valoración por medio de exámenes, mediciones fundadas en estereotipos que anulan la identidad y la individualidad y desde las cuales se construyen calificaciones de las personas. Según, De Souza (2009): "La identidad dominante se reproduce así por dos procesos distintos: por la negación total de lo otro y por la disputa con la identidad subalterna del otro (...)" (p. 297). La violencia se reproduce, conserva y perpetúa, porque es parte y producto del orden social existente en el que se vinculan siempre las luchas entre poderes y clases sociales.

La mediación desde la biopedagogía se orienta a la sensibilización, el compromiso y actitudes relacionales que valoren y recuperen la participación, la cooperación, la coinspiración, desde la cultura de la ternura, la corporeidad y el cuidado.

Cada ser aprendiente merece ser respetado y cuidado desde su esencia misma. Para Boff (2004), “(...) el cuidado expresa la importancia de la razón cordial, que respeta y venera el misterio que es velado y revelado en cada ser del universo (...) el cuidado causa preocupación y despierta el sentimiento de responsabilidad" (p. 67).

¿Qué significa mediar desde la ética del cuidado? Significa entender a los estudiantes y a las estudiantes desde su integralidad comprendiendo la triada mente, cuerpo y espíritu. Por lo tanto, se reconoce que todos y todas tienen voz y que esta vale la pena ser escuchada, se valora el poder de la palabra amable, la sonrisa, el agradecimiento y el mirar a los ojos.

También, se rescata la cotidianeidad para encontrar en el día a día los elementos necesarios para comprender los contenidos programáticos. Significa ofrecer ayudas ajustadas, buscar la orientación adecuada y potenciar la cooperación.

Consiste en dar paso a la pedagogía de la pregunta, que permita el empoderamiento del aprendiente a la luz de la autorreflexión y correflexión. La escolarización, lamentablemente, se olvidó de las preguntas y sus privilegios: pensamiento reflexivo, crítico, creativo.

Es urgente valorar la pregunta como un elemento fundamental de la mediación, pues permite potenciar el pensamiento creativo y da soporte al proceso de autoaprendizaje. Es un principio fundamental en el proceso de aprender a aprender. Para Fried (2001), la pedagogía de la pregunta simplemente nos invita a "(...) Volver a ser niños: Esos pequeños científicos que quieren saber de qué se trata todo" (p. 11).

Es necesario que la mediación se convierta en ese acercamiento provocador que interpela al diálogo y posibilita la construcción de las bases de sistemas educativos incluyentes; que destierre el lenguaje jerárquico, verticalista, fundado en el par dominador-dominado correspondiente al mundo mecanicista, por uno de cooperación y amor. 


\section{Mediar desde la ética del diálogo: ¿De quién es la palabra?}

En la mayoría de instituciones educativas, ¿de quién es la palabra? Esta es una pregunta fácil de contestar, solamente basta con asomarse un poco en las aulas de muchas escuelas, colegios y universidades para visualizar al personal docente frente al estudiantado. Su voz es la única que se escucha $y$, ocasionalmente, una que otra respuesta memorizada del grupo estudiantil. Lamentablemente, el diálogo es casi ausente y la posibilidad de disentir lo es mucho más.

Mediar desde la ética del diálogo implica necesariamente un intercambio de saberes y sentires, eliminar la idea errónea de que la persona docente es quien tiene la palabra, el dominio del conocimiento y el estudiantado no lo tiene. Es necesario comprender que tanto docentes como estudiantes poseen conocimientos y saberes, que son diferentes y complementarios, porque implican experiencias de vida, interconexiones mentales que permiten ampliar la visión del mundo. Para Bohn. (1997), "(...) si compartimos nuestras opiniones sin hostilidad seremos capaces de pensar juntos, algo imposible, por otra parte, cuando nos limitamos a defender nuestras opiniones (...)" (p. 54).

Mediar desde la ética del diálogo exige grandes retos: implica enfrentar las incertidumbres, pero para la mayoría de docentes son más cómodas las certezas. Dialogar exige reflexionar acerca de dónde estamos posicionados en cada momento, pero es más fácil dar por hecho que estamos en el lugar adecuado. También, implica procesos de autorreflexión que permitan comprender cómo el ser humano se transforma; sin embargo, es menos complicado moverse por inercia, sin mucha conciencia de lo que está pasando.

Para mediar desde la ética del diálogo es urgente la comprensión, dejar de lado toda práctica comunicativa que incite al dominio, al poder, a la violencia. Según Morin (1999), "(...) incluye necesariamente un proceso de empatía, de identificación y de proyección. Siempre intersubjetiva, la comprensión necesita apertura, simpatía, generosidad" (p. 51). Se requiere propiciar la libertad, la acción comunicativa, siempre ligada a la democracia. Desde esta perspectiva, reducir o anular el diálogo no es justificable en ningún sistema educativo que diga que persigue construir ciudadanía, autonomía e identidad democrática.

Es fundamental el lenguaje de las interrelaciones, pues marca un cambio que reconoce la necesidad de pensar y accionar de modo interdependiente; que entra en el dominio del pensar solidario, profundamente ligado a la espiritualidad, y el él no hay primacía de jerarquías, sino aceptación del otro como legítimo otro (Maturana, 2002).

Recuperar la palabra, el placer por el encuentro, el intercambio y hacer de cada momento pedagógico una experiencia dialógica: eso sí es ético. De ahí que formar en biopedagogía constituye un reto necesario que deben asumir las universidades de cara a un nuevo milenio que exige crecimiento y madurez espiritual. En este sentido, el caos y la incertidumbre, hoy, constituyen alternativas beneficiosas para la educación, si se comprende que: 
URL: http://www.una.ac.cr/educare

CORREO: educare@una.cr

El caos, por su parte, representa la simplicidad y la complejidad, a la vez; se vislumbra como desorden y orden, como desequilibrio y autopoiésis (palabra que viene de los vocablos griegos autos, que indica sí mismo, y poiesis, que quiere decir producir). (Castillo y Marín, 2009, p. 137)

Por su parte, la incertidumbre permite estar en constante búsqueda, aprender a danzar con las fluctuaciones y hacerles frente de manera creativa, porque la vida es incesantemente compleja, por tanto contingente.

La misión se basa en recuperar la dignidad de muchos seres humanos. Esta ha sido pisoteada y lo sigue siendo, por la intransigencia de políticas educativas burocráticas que, más que apostar a la liberación, han producido la opresión y reproducción de patrones antisolidarios e irrespetuosos.

\section{Mediar desde la ética del respeto y la solidaridad: Una responsabilidad compartida}

Comprender esta ética es entender las interrelaciones y la interdependencia. Desde la vida misma cada quien está entrelazado en una trama de relaciones, cada cosa que se hace afecta el todo. Según Boff (2004):

(...) Nadie se da la vida a sí mismo, la vida se recibe de alguien que nos acoge solidariamente y la introduce en la comunidad de los humanos. Todos dependemos de un plato de comida, de un vaso de agua y de quienes nos aceptan, soportan y deciden convivir con nosotros. (p. 77)

Desde esta solidaridad, mediar significa propiciar experiencias de aprendizaje que permitan a los aprendientes comprenderse a sí mismos, entender su interdependencia y relaciones con los otros y otras, con el mundo y el todo. llustrando estas ideas, Maturana (2002) señala que: "(...) los seres humanos, nos movemos de distinta manera en relación, según como nos relacionemos con nosotros mismos. En el respeto por sí mismo, se encuentra el respeto por el otro y en el respeto por el otro se encuentra el respeto por sí mismo (...)" (p. 243).

Mediar desde la ética de la solidaridad significa generar experiencias de aprendizaje que propicien el deseo de compartir, convivir, buscar y descubrir, sentir la ilusión que representa el compromiso y responsabilidad. Según Boff (2004), "(...) la responsabilidad muestra el carácter ético de la persona. Ésta escucha el llamado de la realidad que resuena en su conciencia y responde a este llamado, una respuesta nunca indiferente, de esta capacidad de respuesta nace la responsabilidad" (p. 72). Este imperativo ético tiene tres concreciones fundamentales:

Responsabilidad con el medio ambiente.

1. Compromiso con la calidad de vida de todos los seres.

2. Deber histórico y responsabilidad generacional. 
Las instituciones educativas no pueden seguir ocultando y silenciando estos imperativos. Desde esta visión se comprende la ética como la posibilidad de defender la vida y cuidarla, la educación tiene que volver su mirada a la valoración de la vida.

Lo que actualmente está o debe estar en el tapete de la reflexión es la defensa de la vida; es tan relevante esta realidad y necesidad, que aun las tendencias más conservadoras admiten que hay una amenaza apremiante que va más allá de la extinción de una gran multitud de especies vivas. Es decir, la vida en general está en peligro y necesita del surgimiento de una nueva conciencia que incluye la mística y la espiritualidad. Para Boff (1996) implica un nuevo pacto del ser humano con todos los demás seres, fundado en una nueva religación.

Desde una ética responsable, la mediación pedagógica está llamada a construir espacios relacionales saludables y solidarios; a crear situaciones de aprendizaje que permitan celebrar la vida y venerarla.

Mediar desde la ética de la responsabilidad y solidaridad significa:

- Construir las bases para la protección del todo.

- Encontrar los momentos y palabras adecuadas para invitar al estudiantado a cuidar el medio ambiente, usar racionalmente los recursos y realizar ejercicios prácticos para tener claridad de la huella ecológica que cada quien impregna.

- Aprovechar cada momento en el compartir pedagógico para mostrar, con el ejemplo, el poder que tiene cada persona para influir positivamente en las otras. Cada sesión de trabajo, cada momento de "clase" puede ser un espacio para recordar el milagro de la vida y la responsabilidad que se tiene con las generaciones futuras.

- Implica pensar más allá del contenido literal, para encontrar las relaciones entre este y lo que se hace, para aprovechar cada momento pedagógico para apelar a la ética. Ejercer la docencia desde la mediación de la responsabilidad y solidaridad no es una tarea sencilla, pues implica salir de la comodidad del estado de confort que genera la rutina.

No vale la pena que las instituciones educativas formen profesionales altamente conocedores de su materia pero que no saben convivir en la diversidad o no pueden valorar las implicaciones de sus actos.

Comprender el latido y lamento de la tierra no se enseña, se vive. Las personas docentes tenemos la responsabilidad de generar momentos innumerables para escuchar lo que el ruido del tedio y la rutina no permite, para mirar más allá de lo que no se mira por estar cegados por la cultura esclavizadora de memorización y fragmentación. 
URL: http://www.una.ac.cr/educare

CORREO: educare@una.cr

\section{Reflexiones finales y aportes}

En un siglo caracterizado por el aislamiento y la deshumanización, es necesario trabajar en alternativas que favorezcan la legitimidad de los otros y otras, como auténticos seres con derechos. Desde los sistemas educativos, es posible generar una forma de vínculo social alternativo donde la diferencia se convierta en la fortaleza.

El abordaje en la praxis de aspectos como libertad, respeto mutuo, integralidad, solidaridad e inclusión, deben ser afianzados. La ética constituye esa afirmación de la libertad.

Por tanto, reflexionar sobre la mediación pedagógica desde una perspectiva ética, implica cuestionarse el tipo de relaciones y acciones humanas en contextos cotidianos, porque es en estas tramas sociales, donde se instauran principios y valores relevantes en la vida de las personas.

Los procesos educativos deben estar enfocados al reconocimiento y validación de la pluralidad; la reflexión ética se interconecta con el cumplimiento de los derechos humanos en su ámbito individual y colectivo. De ahí que se afirme que la ética no prescribe; la ética suscita y exige compromiso en la forma de conectarse e implicarse en la vida y con ella.

Bateson (1993) pregunta:

(...) ¿Por qué los establecimientos educativos no enseñan casi nada acerca de la pauta que conecta? ¿Acaso los maestros saben que llevan consigo el beso de la muerte que torna insípido todo cuanto tocan, y entonces se niegan sabiamente a tocar o enseñar cualquier cosa que posea importancia para la vida real? ¿O es que portan el beso de la muerte porque no se atreven a enseñar nada de importancia. [sic] para la vida real? ¿Qué es lo que les pasa?

¿Qué pauta conecta al cangrejo con la langosta y a la orquídea con el narciso, y a los cuatro conmigo? ¿Y a mí contigo? (p. 18)

Desde esta perspectiva se requiere una mirada que profundice en el origen social y el sentido de lo humano, además de la esencia de la pedagogía como ciencia formativa en función de la vida. La visión ética de la biopedagogía tiene que favorecer una mediación fundamentada en la justicia; que permita pensar y actuar de modo consciente y reflexivo, para lo cual se requiere la comprensión e interpretación del significado de la libertad. Implica potenciar la inteligencia y la formación de hábitos virtuosos basados en valores que permitan obrar en virtud de la defensa de la existencia.

A nivel universitario, es posible mediar desde la ética, propiciando el hábito de la crítica constructiva, aquella de la cual se aprende y reaprende. Ejercitar el escrutinio y la deliberación son aspectos esenciales, dada la dominancia de un sistema socioeconómico que invita a pensar la formación en términos de tener. 
Algunas experiencias de mediación valiosas pueden ser el estudio de casos, el juego de papeles, la lectura aguda que permita y sugiera las formas diferentes de interpretación que consideren principios y criterios éticos en contextos reales.

Se trata de ir más allá de una educación moral, más lejos de la instrucción de reglas y normas, dado que el conocimiento de estas no certifica que una persona cumpla con lo que estas indican. La mediación biopedagógica, desde una perspectiva ética, exige buscar estrategias comunicativas que permitan el ejercicio del disenso para llegar a consensos.

En este contexto, el lenguaje constituye un elemento fundamental para generar tejidos donde se reconozca la otredad a partir de experiencias relacionales consigo mismo y con otras personas y seres vivos.

El cambio hacia una visión biopedagógica requiere modificar y desarrollar proyectos educativos anclados en proyectos de vida que permitan valorar las diferencias en el actuar y en el sentir evitando reduccionismos.

La pedagogía debe potenciar los intercambios argumentativos que permitan la reflexión, el análisis, la comprensión; el no perder de vista la complejidad; favorecer el aprendizaje cooperativo a la luz de experiencias donde prevalezca el debate, la deliberación; consolidar proyectos educativos comunes que permitan compartir ideales, sueños y esperanzas -siempre tan necesaria para la subsistencia de la vida-; escudriñar en el orden social vigente para lograr trascenderlo y transformarlo.

La ética, desde una visión biopedagógica, implica actuación consciente y libre de las personas; no puede ser una imposición. Hay que formar en la libertad, la cual requiere gobierno del propio ser, tal y como lo manifiesta Freire (2011). En este sentido, Fradera y Guardans (2008) también consideran necesario el cultivar la interioridad, denominada por las autoras la "séptima dirección".

Buscar la séptima dirección es, también favorecer la autonomía personal. Que las decisiones se apoyen, cada vez más, en la certeza interior, en el sabor de verdad, en la reflexión compartida e individual. Es valorar las fortaleza, los intentos y el ánimo de reto más que la perfección de unos resultados. Es trasmitir que el verdadero éxito reside en la constancia: revisar, modificar, insistir (...). (p. 7)

Lo anterior implica formar en las emociones, en los sentimientos, solo así se puede tener la suficiente motivación para actuar correctamente. Hoy más que nunca se reconoce que lo afectivo es un imperativo en el que tiene que fundamentarse la biopedagogía, es la esperanza de lograr aprendizajes más sociales, humanos, vitales; eso concatena la esperanza. 
URL: http://www.una.ac.cr/educare

CORREO: educare@una.cr

En el descubrimiento de lo emotivo se construyen conocimientos relevantes. La disposición afectiva, la empatía, la manifestación de las emociones, son fundamentales para que se dé el aprendizaje auténtico. Cabe recordar que el mundo se mueve por pasiones hacia ideas y valores. Se requiere una nueva manera de comprender la educación, la pedagogía, el currículo, la didáctica: Necesitamos direccionar nuestras energías y sabiduría para poder visualizar transformación.

\section{Referencias}

Alvarado, E. (2007). Educación, ecología y economía: Pasos hacia otra epistemología. Costa Rica: Alma Mater.

Assman, H. (2002). Placery ternura en educación. Hacia una sociedad aprendiente. Madrid: Narcea.

Bateson, G. (1993). Espíritu y naturaleza. Buenos Aires: Amorrurto

Boff, L. (1996). Ecología: Grito de la tierra, grito de los pobres. Madrid: Trota.

Boff, L. (2004). Ética planetaria desde el Gran Sur. México: Dabar.

Bohn, D. (1997). Sobre el diálogo (2a ed., Trad. D. González y F. Mora). Barcelona: Kairós.

Castillo, I. y Marín, C. (junio, 2009). Hacia una visión holística de la educación universitaria: El amor y el caos un proceso creativo para el aprendizaje. Revista Electrónica Educare, 13(1), 135-143. Recuperado de http://www.revistas.una.ac.cr/index.php/EDUCARE/article/ view/1481

De Souza, B. (2009). Una epistemología del sur. La reinvención del conocimiento y la emancipación social. México: Siglo XXI.

Fradera, M. y Guardans, T. (2008). La séptima dirección. El cultivo de la interioridad. Barcelona: (CETR)

Freire, P. (2011). La educación como práctica de la libertad. Buenos Aires: Siglo veintiuno.

Fried, R. (2001). La pasión de aprender. Santiago: Cuatro vientos.

Gutiérrez, F. (2004). Pedagogía del aprendizaje. Guatemala: USAC.

Hernández, S. M. (2010). Educación y ética. Sociológica, 25(72), 215-227. Recuperado de http:// scielo.unam.mx/pdf/soc/v25n72/v25n72a10.pdf

Maturana, H. (2002). Transformación en la convivencia. Santiago: Dolmen. 
URL: http://www.una.ac.cr/educare CORREO: educare@una.cr

Morin, E. (1999). Los siete saberes necesarios para la educación del futuro. Unesco.

Osorio, J. y Weinstein, L. (1995) El corazón del arco iris: Lecturas sobre nuevos paradigmas en educación y desarrollo. Santiago: CEAAL

Pasillas, M. A (2005) Violencia, ética y pedagogía. Revista Mexicana de investigación educativa. 10(27), 1149-1164. Recuperado de http://redalyc.uaemex.mx/pdf/140/14002711.pdf

\section{Cómo citar este artículo en APA:}

Castillo, I. y Castillo, R. (2013). La mediación biopedagógica desde una perspectiva ética. Revista Electrónica Educare, 17(2), 111-121. Recuperado de http://www.revistas.una. ac.cr/index.php/EDUCARE/issue/current

Nota: Para citar este artículo en otros sistemas puede consultar el hipervínculo "Como citar el artículo" en la barra derecha de nuestro sitio web:

http://www.revistas.una.ac.cr/index.php/EDUCARE/index 